\title{
Review
}

\section{Eleni Gavriilaki, Ioannis Eftychidis and Ioannis Papassotiriou* Update on endothelial dysfunction in COVID-19: severe disease, long COVID-19 and pediatric characteristics}

https://doi.org/10.1515/labmed-2021-0134

Received September 21, 2021; accepted October 2, 2021;

published online October 18, 2021

\section{Abstract}

Objectives: To review current literature on the role of endothelial dysfunction in coronavirus disease-2019 (COVID-19) infection in terms of pathophysiology, laboratory features and markers, clinical phenotype in adults and children, as well as long COVID-19.

Content: We conducted a thorough assessment of the literature and critically analyzed current data, mostly utilizing the PubMed and Medline search engines to find original studies published in the previous decade.

Summary and Outlook: Accumulating evidence suggests that endothelial dysfunction may be a common denominator of severe COVID-19 in adults and children, as well as long COVID-19, implicating mutual pathophysiological pathways. This narrative review summarizes the up-to-date knowledge of endothelial dysfunction caused by COVID-19, including novel aspects of long COVID-19 and pediatric disease. This knowledge is important in order not only to understand the multisystemic attack of COVID-19, but also to improve patient management and prognosis.

Keywords: COVID-19; endothelial dysfunction; long COVID-19; pediatric; SARS-COV-2; thrombosis.

\section{Introduction}

Coronavirus disease-2019 (COVID-19) has dramatically changed every perspective of human life worldwide, with

*Corresponding author: Ioannis Papassotiriou, PhD, Department of Clinical Biochemistry, “Aghia Sophia” Children's Hospital Athens, Greece; and IFCC Emerging Technologies Division, Emerging Technologies in Pediatric Laboratory Medicine (C-ETPLM), Milan, Italy, Phone: +30-213-2013931, E-mail: biochem@paidon-agiasofia.gr Eleni Gavriilaki and Ioannis Eftychidis, Hematology Department BMT Unit, G. Papanikolaou Hospital, Thessaloniki, Greece unprecedented morbidity and mortality [1]. Despite extensive efforts in vaccination programs, severe COVID-19 continues to represent a threat to public health, with long-term effects of the disease just being discovered [2]. Given the lack of an early prognostic model or a successful treatment regimen, better understanding of disease pathophysiology is still warranted [3].

A main pathophysiological process in severe and/or long COVID-19 involves endothelial dysfunction, which has been a key feature of several viral infections, including previous coronaviruses [4, 5]. Experimental, laboratory and clinical evidence from previous coronaviruses have triggered studies testing hypotheses on the role of SARS-CoV-2 (severe acute respiratory syndrome coronavirus 2) in endothelial dysfunction [6]. Indeed, endothelial dysfunction appears to be the common denominator of multiple clinical aspects of severe COVID-19 that have been challenging for treating physicians [7]. Therefore, we performed a PubMed and Medline search for original articles using the following keywords: COVID-19; endothelial dysfunction; thrombosis; long COVID-19; pediatric; SARS-COV-2. Articles were evaluated and included in this review based on their relevance and originality.

\section{Pathophysiology of endothelial dysfunction}

Endothelium represents a continuous monolayer of endothelial cells forming the inner cellular lining of arteries, veins and capillaries. It serves as a barrier between tissues and blood with the functional capacity of an endocrine organ. Endothelium dynamically interacts with blood components and other circulating cells, participating in a number of pathophysiological processes $[8,9]$.

Under physiological conditions, it restores vascular integrity upon vascular injury and inhibits excessive thrombosis and clot formation by interacting with coagulation [9]. It is also involved in recruitment, adhesion and interaction of platelets and leucocytes with thrombogenic 
surfaces. Furthermore, endothelium regulates vascular tone and growth by synthesizing and releasing both vasodilatory factors, such as nitric oxide (NO), and endothelium-derived contracting factors, such as endothelin and angiotensin II $[8,10]$. NO biosynthesis plays the most important role for maintenance of vascular homeostasis [11].

Under conditions of increased oxidative stress, biosynthesis and availability of NO are diminished [12]. The endothelium loses its protective properties, shifting towards impaired vasodilation and expression of a proinflammatory, pro-atherosclerotic, and pro-thrombotic profile [13]. Endothelial dysfunction has been documented early in the course of cardiovascular disease by use of several vascular or functional markers, such as the gold-standard flow-mediated vasodilation (FMD), or by measurement of circulating biomarkers, that will be further discussed in the section on laboratory markers $[14,15]$.

In severe infectious diseases, including viral infections, endothelial dysfunction and thrombosis interact in a vicious cycle. Free radicals damage the endothelium by quenching $\mathrm{NO}$ and allowing toxins to pass into underlying tissues through the disrupted endothelium. Vascular leakage is a prominent feature of endothelial dysfunction in such cases, caused either directly by the viral attack or indirectly by excessive endothelial activation due to maladaptive immunological responses [9].

\section{Previous coronaviruses and endothelial dysfunction}

Two decades ago, the SARS epidemic was caused by the SARS-CoV that primarily targeting pneumocytes and enterocytes, that abundantly express angiotensin-converting enzyme 2 (ACE2), the main functional SARS-CoV receptor. Since endothelial cells express ACE2 in several organs, early studies suggested endothelial dysfunction in SARS patients [16-21].

Given the interaction between endothelial dysfunction and thrombosis, coronavirus infected patients (SARS-CoV and Middle East respiratory syndrome/MERS-CoV) have shown in vitro and in vivo a pro-coagulant profile [22-27]. In the laboratory, this interaction has been shown by increased levels of thrombopoietin, von Willebrand factor (vWF), and plasminogen activator inhibitor-1 (PAI-1) in SARS patients $[28,29]$. In postmortem studies, 20 autopsies from SARS patients revealed vascular endothelial damage of both small- and medium-sized pulmonary vessels and multiple intravascular fibrin thrombi and thromboemboli associated with pulmonary infarctions [20]. Another postmortem analysis of an individual SARS patient documented evidence of endothelial cell inflammation and thromboemboli in the veins and microcirculation of multiple organs, thereby highlighting the thrombogenic potential of SARS-CoV in a wider spectrum of tissues, including the systemic vasculature [21].

An integral part of this vicious cycle of endothelial dysfunction and thrombosis is also complement activation [30]. Indeed, studies of previous coronaviruses have shown that blocking $\mathrm{C} 3$ activation significantly attenuates the lungdirected proinflammatory sequelae of infections. Both the genetic absence of $\mathrm{C} 3$ and blockade of downstream complement effectors, have shown therapeutic promise by containing the detrimental proinflammatory consequences of viral spread mainly via inhibition of monocyte/neutrophil activation and immune cell infiltration into the lungs [31].

Overall, these studies from previous coronaviruses have been of utmost importance for generating hypotheses and forming the background of further studies in COVID-19.

\section{Endothelial dysfunction in COVID-19 infection}

\section{Pathophysiology}

The key to understand a new complex pathophysiological process is to combine experimental and translational research applying a bench-to-bedside approach. In this context, several groups worldwide have shown evidence of complement activation in experimental and clinical studies of severe COVID-19 [32-38]. Complement activation and neutrophil extracellular traps have shaped the concept of thromboinflammation or immunothrom bosis in COVID-19 [39]. Based on the paradigm of genetic susceptibility in complement-mediated disorders or complementopathies [40], our group and others have suggested genetic susceptibility identifying complement genetic variants in COVID-19 patients [3, 41, 42]. In parallel, complement inhibitors have shown safety and efficacy in severe COVID-19 during the first wave [31]. Encouraging results have been reported in case series for terminal complement inhibition with eculizumab [43], C3 inhibition with the compstatin-based inhibitor AMY-101 [44], and lectin pathway inhibition with narsoplimab [45]. Further comparative results of AMY-101 to eculizumab point toward a broader pathogenic involvement of C3-mediated pathways in thromboinflammation [46]. Given 
the promising data, randomized controlled trials are ongoing for AMY-191 and eculizumab in severe COVID-19 (NCT04346797, NCT04395456).

Other angles of the pathophysiology of endothelial dysfunction in COVID-19 have focused on pericytes with high expression of ACE2 as target cells of COVID-19, resulting in endothelial cell and microvascular dysfunction. Given that ACE2 is highly expressed on cardiac myocytes, cardiac injury is found in COVID-19 [47]. Similarly, a coronaviral tropism for the kidney has been also suggested, since ACE2 is highly expressed on podocytes and tubular epithelial cells of the kidney [48]. What still remains puzzling, is the neuroinvasive potential of SARS-CoV-2 hypothesized by neurological signs and symptoms. Interestingly, behavioral problems, childhood tics and tic-like attacks, have been also reported [49]. ACE2 is expressed in the vasculature of the brain [50], leading to the hypothesis that endothelial injury ruptures cerebral capillaries and may be responsible for fatal intracerebral hemorrhage in COVID-19 [51]. In postmortem studies, the first evidence of SARS-CoV-2 presence in brain tissue strongly supported this hypothesis of endothelial injury and hematogenous dissemination as the primary route of central nervous system (CNS) invasion [52]. Viral RNA has been also detected in autopsies of infected patients [53]. Alternative routes of direct nervous system invasion or an indirect immune-mediated involvement of CNS are also under consideration.

\section{Laboratory markers}

The numerous circulating inflammatory coagulation biomarkers directly implicated in clotting, with an emphasis on fibrin (ogen), D-dimer, P-selectin, and von Willebrand factor (vWF), are of special interest. Their changes cause an imbalance between procoagulant and anticoagulant factors, for example, fibrinogen induces thrombus formation, whereas decrease in high molecular vWF enhances bleeding [54].

\section{Fibrinogen}

Fibrinogen is a protein that is increased during the acute phase of inflammation [55]. Elevation in fibrinogen levels can be linked to hypercoagulability and endothelial dysfunction. On the other hand, thrombocytopenia and low levels of fibrinogen have been associated to bleeding disorders [56]. (Measurement: In vitro diagnostics (IVD) available in automated platforms).

\section{Von Willebrand factor (vWF) antigen}

Endothelial cells and megakaryocytes are the only cells that produce vWF [57]. vWF plays a key role in platelet agglomeration and clot formation, and it is classed as an acute phase factor due to its importance in inflammation [58]. vWF is also known to be involved in the progression of atherosclerosis through increasing plaque creation and inflammation [59]. Furthermore, vWF binds circulating platelets to the endothelium as part of the thrombosis, inflammation, and tumor development processes [60]. vWF:antigen is both a hemorrhage (when decreased) and coagulation (when increased) indicator in normal circumstances, which is a crucial factor for COVID-19 pathology [61]. (Measurement: IVD available in automated platforms).

\section{D-dimers}

D-dimers are not typically detected unless thrombosis has occurred, therefore they can be used as a thrombosis indicator [62,63]. D-dimer levels are normal or slightly elevated at the early stages of COVID-19, but as the patient's condition deteriorates, D-dimer levels are considerably elevated. Assessing D-dimer levels early after admission and continuing to monitor them afterward might help identify individuals with heart damage and predict further COVID-19 complications [64]. It should be noted however, that a raised troponin has been identi fied as a better prognostic marker of heart damage [65] (Measurement: IVD available in automated platforms).

\section{P-selectin}

P-selectin, also known as CD62P, is a protein that regulates the interactions of blood cells with endothelial cells [66]. P-selectin functions as an adhesion receptor on the cell membrane, allowing leukocytes to roll and emigrate at inflammatory areas [67]. As endothelial cells and platelets store and express P-selectin, there has been much discussion about whether elevated P-selectin levels in the blood reflect endothelial dysfunction, platelet activation, or both [66]. Soluble P-selectin (sP-selectin) is the product of spliced P-selectin, lacking the transmembrane part. 
Circulating sP-selectin is considered to activate leukocyte signaling, which plays a significant role in inflammation and thrombosis. sP-selectin, on the other hand, is most likely circulating as a monomer, and in vitro studies suggest that sP-selectin needs to dimerize to trigger activation in leukocytes [68]. In COVID-19 patients, elevated concentrations of sP-selectin have been linked to an increased risk of thrombosis [69]. (Measurement: Research Use Only (RUO) available only enzyme-linked immunosorbent assay (ELISA))

\section{Clinical phenotype}

Thrombosis: the above-mentioned pathophysiology predisposes COVID-19 patients to a whole spectrum of thrombotic events, including microvascular thrombosis, venous thromboembolism, cardiovascular, and cerebrovascular events [40, 70].

\section{Microvascular thrombosis}

Microvascular thrombosis has been recognized early in the COVID-19 pandemic by post-mortem findings indicating pulmonary vascular endotheliitis, thrombosis, and angiogenesis as a unique feature of COVID-19 [33, 71]. In particular, COVID-19 has been characterized a microvascular disease [72], and some authors have suggested the terminology MicroCLOTS (microvascular COVID-19 lung vessels obstructive thromboinflammatory syndrome) [73].

\section{Venous thromboembolism}

Venous thromboembolism (VTE) manifesting as deep vein thrombosis (DVT) or pulmonary embolism (PE) is common in severe COVID-19 despite prophylactic anticoagulant treatment. Up to now, a plethora systematic reviews and meta-analyses have tried to summarize the data among thousands of COVID-19 patients, with the highest reported incidence of VTE at $42 \%$ in severe COVID-19 patients requiring intensive care unit hospitalization [74-90]. This very high-risk sub-group of COVID-19 patients certainly showed increased VTE incidence compared to non-COVID-19 cohorts [91]. These repeated reports of high VTE rates have necessitated relevant guidelines and recommendations of aggres sive thromboprophylaxis dosing intensities, extendedduration post-discharge thromboprophylaxis and an individualized approach, considering average body mass index, severe thrombocytopenia and drug-to-drug interactions [92-95].

\section{Acute limb ischemia}

Acute upper or lower extremity/limb ischemia (ALI) is an arterial thrombotic complication, often described as a first COVID-19 manifestation. Several cohorts have shown clinical characteristics and treatment options [96-98], suggesting that ALI occurs despite prophylactic anticoagulation and needs surgical intervention.

\section{Cardiovascular events}

From the dawn of the pandemic, acute cardiac injury was observed in 5 out of the first 41 COVID-19 patients in Wuhan, 4 of them required ICU hospitalization, suggesting that cardiac involvement was a predictor of disease severity [99]. Since then, numerous studies and several meta-analyses have tried to clarify the incidence and prognostic importance of cardiovascular events in COVID-19. Indeed, cardiovascular complications are frequent among COVID-19 patients, especially those requiring ICU hospitalization, and contribute to adverse clinical events and mortality [100-102]. Pre-existing cardiovascular comorbidities and risk factors, including diabetes mellitus [103], hypertension [104], and obesity [105], are associated with increased morbidity and mortality in COVID-19 [106]. Assessment of cardiac injury biomarkers may improve identification of those patients at the highest risk [107]. Major cardiac complications include myocardial injury and arrhythmia $[108,109]$. Interestingly, a recent study from the Mayo Clinic, USA has shown that the mechanism of injury to the myocardium in 19/20 cases was not due to myocardial ischemia but hyperinflammatory process [110]. Acute cardiac injury in COVID-19 patients is more frequent than what was expected at the beginning of the outbreak, reaching an incidence of $28 \%$ [111-113].

\section{Cerebrovascular events}

Although less common than cardiovascular events, ischemic cerebrovascular events are recognized as an extra-pulmonary thromboembolic clinical feature in COVID-19. Stroke has been reported as the presenting clinical feature in COVID-19, and not simply a complication of in-hospital stay [114]. Further reviews and metaanalyses have confirmed an average incidence of stroke 
ranging from 1.1 to $4.3 \%$ in COVID-19 [102, 115-121]. Mortality is also high in these patients, reaching $31.76 \%$ [115]. Interestingly, rates of cerebrovascular disease in COVID-19 patients with neurological manifestations have been reported significantly increased compared to hospitalized neurological patients without COVID-19 and associated with statistically significant worse outcomes [122]. The other side of cerebrovascular events, intracerebral haemorrhage (ICH), has also been reported COVID-19, but less frequently [123-126].

\section{Neurological complications}

Beyond cerebrovascular events, neurological manifestations are frequently reported in COVID-19 patients, including smell impairment, taste impairment, myal gia, headache, dizziness, and syncope [127]. Reported neurological complications include encephalopathy, encephalitis, seizures oculomotor nerve palsy, isolated sudden-onset anosmia, Guillain-Barré syndrome, and Miller-Fisher syndrome [128, 129]. The incidence of encephalopathy has been documented up to 9.14\% [130].

\section{Long COVID-19}

A significant proportion of patients who recovered from COVID-19 continue to suffer from various complications, collectively called "long COVID-19" or post COVID-19 syndrome [131]. Although there are no established diagnostic criteria, symptoms of COVID-19 include new or persistent fatigue, dyspnea, joint pain, chest pain, cough, palpitations, anosmia, dysgeusia, alopecia, cognitive blunting, and psychological distress, which cannot be attributed to other causes in patients with preceding SARS-COV-2 infection [132]. In a study of 287 survivors, almost $90 \%$ of patients suffered from several manifestations, with the most common symptom being fatigue (72.8\%), and more critical manifestations including stroke, renal failure, myocarditis and pulmonary fibrosis [133]. Although SARS-CoV-2 infects endothelial cells resulting in autonomic dysfunction in acute infection, a recent study showed that post-COVID-19 fatigue is not associated with autonomic dysfunction [134]. Preliminary findings include extensive lung thrombosis and persistence of SARS-CoV-2 and syncytia in pneumocytes of 41 post-mortem samples, and weakened lung function and lung damage in imaging of 40 patients with persisting shortness of breath [135]. Interestingly, SARS-CoV-2 has been also detected in the penis long after the initial infection, suggesting a link between COVID-19 endothelial dysfunction and erectile dysfunction [136]. In association with long COVID-19, cardiovascular changes have been also observed through imaging modalities [137]. Lastly, little is known regarding the pathophysiology of long COVID-19, although many of the observed symptoms and syndromes may be linked to endothelial dysfunction. In a recent study of 92 patients, COVID-19 disease was an independent predictor of endothelial dysfunction detected by FMD two months after discharge [138].

\section{Characteristics of pediatric patients}

Since the early days of COVID-19, it has been reported that children had milder symptoms when compared to adult patients [139]. Despite the mildness of COVID-19 in children, severe hyperinflammatory diseases occurring 2-4 weeks after an acute infection with SARS-CoV-2 have emerged [140-145]. The symptoms of this condition, known as multisystem inflammatory syndrome in children (MIS-C), are similar to those of Kawasaki disease. In up to $25 \%$ of cases, Kawasaki manifests as an acute vasculitis (mostly affecting medium-sized arteries) in children under the age of five, with fever, lymphadenitis, and coronary artery involvement [146]. Self-reactive antibodies are produced during an acute immune response to a viral infection, most likely at mucosal surfaces and centered around IgA-producing plasma cells, according to the most popular explanation for the pathogenesis of Kawasaki disease [147]. Prior immunity to other viruses may alter their responses to SARS-CoV-2 infection and cause hyperinflammation through antibody-media ted enhancement or other mechanisms, which might explain why some children acquire MIS-C [148]. In all trials to date, the majority of children exhibited elevated markers of myocardial damage, and many had echocardiography abnormalities and/or significant echogenic coronary arteries [141, 144, 145]. Furthermore, a substantial proportion of children had elevated coagulation markers when tested and acute renal damage occurred in $22 \%$ of hospitalized children in an English cohort [142]. According to a multicenter retrospective cohort study in the United States, the rate of thrombotic complications was low in children age under 12 with COVID-19 or MIS-C, but high in children with factors such as age over 12, MIS-C, central venous catheter and cancer [149]. Lastly, data on long COVID-19 in pediatric patients are limited. Ongoing studies, such as the CLoCK one, are expected to provide additional insights [150]. 


\section{Conclusions and future perspectives}

Our review summarizes state-of-the-art knowledge of endothelial dysfunction caused by COVID-19, including novel aspects of long COVID-19 and pediatric disease. Our data are in agreement with previous and recently acquired knowledge that endothelial dysfunction is a common denominator of these processes. This knowledge is important in order not only to understand the multisystemic attack of COVID-19, but also to improve patient management and prognosis. Despite the lack of direct therapeutic agents for endothelial dysfunction, several treatments might affect endothelial dysfunction, with complement inhibitors being a promising strategy. Taking into account the detrimental short- and long-term effects of COVID-19, further studies are warranted to translate these data into clinical practice.

Acknowledgments: Given the broad scope of this review, the authors often refer to specialized review articles rather than primary literature, and they have been able to include only selected examples of original work in the field. Therefore, the authors thank colleagues who are not specifically cited for their contribution and their understanding. E.G. is supported by the AMERICAN SOCIETY OF HEMATOLOGY (ASH) Global Research Award 2020.

Research funding: None declared.

Author contribution: E.G. researched the literature and contributed to discussions of the content and wrote the paper. I.S. selected the publicly available data from the original investigations quoted in the manuscript and contributed to discussion of the content and wrote the paper. I.P. Conceptualization researched the literature and contributed to discussions of the content and wrote the paper. All authors wrote the text and edited the manuscript before submission.All authors have accepted responsibility for the entire content of this manuscript and approved its submission.

Competing interests: Authors state no conflict of interest. Informed consent: Not applicable.

Ethical approval: Not applicable.

\section{References}

1. Kabanova A, Gavriilaki E, Pelzer BW, Brunetti L, Maiques-Diaz A. Effect of the COVID-19 pandemic on laboratory and clinical research: a testimony and a call to action from researchers. Hemasphere 2020;4:e499.
2. Phillips S, Williams MA. Confronting our next national health disaster - long-haul covid. N Engl J Med 2021;385:577-9.

3. Gavriilaki E, Asteris PG, Touloumenidou T, Koravou EE, Koutra M, Papayanni PG, et al. Genetic justification of severe COVID-19 using a rigorous algorithm. Clin Immunol 2021;226:108726.

4. Steinberg BE, Goldenberg NM, Lee WL. Do viral infections mimic bacterial sepsis? The role of microvascular permeability: a review of mechanisms and methods. Antivir Res 2012;93:2-15.

5. Goeijenbier M, van Wissen M, van de Weg C, Jong E, Gerdes VE, Meijers JC, et al. Review: viral infections and mechanisms of thrombosis and bleeding. J Med Virol 2012;84:1680-96.

6. Gavriilaki E, Anyfanti P, Gavriilaki M, Lazaridis A, Douma S, Gkaliagkousi E. Endothelial dysfunction in COVID-19: lessons learned from coronaviruses. Curr Hypertens Rep 2020;22:63.

7. Varga Z, Flammer AJ, Steiger P, Haberecker M, Andermatt R, Zinkernagel AS, et al. Endothelial cell infection and endotheliitis in COVID-19. Lancet 2020;395:1417-8.

8. Michiels C. Endothelial cell functions. J Cell Physiol 2003;196: 430-43.

9. Rajendran P, Rengarajan T, Thangavel J, Nishigaki Y, Sakthisekaran D, Sethi G, et al. The vascular endothelium and human diseases. Int J Biol Sci 2013;9:1057-69.

10. Godo S, Shimokawa H. Endothelial functions. Arterioscler Thromb Vasc Biol 2017;37:e108-14.

11. Bevers LM, Braam B, Post JA, van Zonneveld AJ, Rabelink TJ, Koomans HA, et al. Tetrahydrobiopterin, but not L-arginine, decreases NO synthase uncoupling in cells expressing high levels of endothelial NO synthase. Hypertension 2006;47: 87-94.

12. List BM, Klosch B, Volker C, Gorren AC, Sessa WC, Werner ER, et al. Characterization of bovine endothelial nitric oxide synthase as a homodimer with down-regulated uncoupled NADPH oxidase activity: tetrahydrobiopterin binding kinetics and role of haem in dimerization. Biochem J 1997;323:159-65.

13. Gkaliagkousi E, Gavriilaki E, Triantafyllou A, Douma S. Clinical significance of endothelial dysfunction in essential hypertension. Curr Hypertens Rep 2015;17:85.

14. Gkaliagkousi E, Gavriilaki E, Vasileiadis I, Nikolaidou B, Yiannaki $\mathrm{E}$, Lazaridis A, et al. Endothelial microvesicles circulating in peripheral and coronary circulation are associated with central blood pressure in coronary artery disease. Am J Hypertens 2019; 32:1199-205.

15. Gkaliagkousi E, Gavriilaki E, Triantafyllou A, Nikolaidou B, Anyfanti P, Koletsos N, et al. Asymmetric dimethylarginine levels are associated with augmentation index across naive untreated patients with different hypertension phenotypes. J Clin Hypertens 2018;20:680-5.

16. Guo Y, Korteweg C, McNutt MA, Gu J. Pathogenetic mechanisms of severe acute respiratory syndrome. Virus Res 2008;133:4-12.

17. Hamming I, Timens W, Bulthuis ML, Lely AT, Navis G, van Goor H. Tissue distribution of ACE2 protein, the functional receptor for SARS coronavirus. A first step in understanding SARS pathogenesis. J Pathol 2004;203:631-7.

18. Yang YH, Huang YH, Chuang YH, Peng CM, Wang LC, Lin YT, et al. Autoantibodies against human epithelial cells and endothelial cells after severe acute respiratory syndrome (SARS)-associated coronavirus infection. J Med Virol 2005;77:1-7.

19. Ding Y, Wang H, Shen H, Li Z, Geng J, Han H, et al. The clinical pathology of severe acute respiratory syndrome (SARS): a report from China. J Pathol 2003;200:282-9. 
20. Hwang DM, Chamberlain DW, Poutanen SM, Low DE, Asa SL, Butany J. Pulmonary pathology of severe acute respiratory syndrome in Toronto. Mod Pathol 2005;18:1-10.

21. Xiang-Hua Y, Le-Min W, Ai-Bin L, Zhu G, Riquan L, Xu-You Z, et al. Severe acute respiratory syndrome and venous thromboembolism in multiple organs. Am J Respir Crit Care Med 2010;182:436-7.

22. Giannis D, Ziogas IA, Gianni P. Coagulation disorders in coronavirus infected patients: COVID-19, SARS-CoV-1, MERS-CoV and lessons from the past. J Clin Virol 2020;127: 104362.

23. Gralinski LE, Baric RS. Molecular pathology of emerging coronavirus infections. J Pathol 2015;235:185-95.

24. Gralinski LE, Bankhead 3rd A, Jeng S, Menachery VD, Proll S, Belisle SE, et al. Mechanisms of severe acute respiratory syndrome coronavirus-induced acute lung injury. mBio 2013;4. https://doi.org/10.1128/mBio.00271-13.

25. Tang BS, Chan KH, Cheng VC, Woo PC, Lau SK, Lam CC, et al. Comparative host gene transcription by microarray analysis early after infection of the Huh7 cell line by severe acute respiratory syndrome coronavirus and human coronavirus $229 \mathrm{E}$. J Virol 2005;79:6180-93.

26. Han M, Yan W, Huang Y, Yao H, Wang Z, Xi D, et al. The nucleocapsid protein of SARS-CoV induces transcription of hfgl2 prothrombinase gene dependent on C/EBP alpha. J Biochem 2008;144:51-62.

27. Ng LF, Hibberd ML, Ooi EE, Tang KF, Neo SY, Tan J, et al. A human in vitro model system for investigating genome-wide host responses to SARS coronavirus infection. BMC Infect Dis 2004; 4:34.

28. Yang M, Ng MH, Li CK, Chan PK, Liu C, Ye JY, et al. Thrombopoietin levels increased in patients with severe acute respiratory syndrome. Thromb Res 2008;122:473-7.

29. Wu YP, Wei R, Liu ZH, Chen B, Lisman T, Ren DL, et al. Analysis of thrombotic factors in severe acute respiratory syndrome (SARS) patients. Thromb Haemostasis 2006;96:100-1.

30. Gavriilaki E, Chrysanthopoulou A, Sakellari I, Batsis I, Mallouri $\mathrm{D}$, Touloumenidou T, et al. Linking complement activation, coagulation, and neutrophils in transplant-associated thrombotic microangiopathy. Thromb Haemostasis 2019;119: 1433-40.

31. Risitano AM, Mastellos DC, Huber-Lang M, Yancopoulou D, Garlanda C, Ciceri F, et al. Complement as a target in COVID-19? Nat Rev Immunol 2020;20:343-4.

32. Gao T, Hu M, Zhang X, Li H, Zhu L, Liu H, et al. Highly pathogenic coronavirus $\mathrm{N}$ protein aggravates lung injury by MASP2-mediated complement over-activation. medRxiv 2020. https://doi.org/10.1101/2020.03.29.20041962.

33. Magro C, Mulvey JJ, Berlin D, Nuovo G, Salvatore S, Harp J, et al. Complement associated microvascular injury and thrombosis in the pathogenesis of severe COVID-19 infection: a report of five cases. Transl Res: J Lab Clin Med 2020;220:1-13.

34. Yu J, Yuan X, Chen H, Chaturvedi S, Braunstein EM, Brodsky RA Direct activation of the alternative complement pathway by SARS-CoV-2 spike proteins is blocked by factor D inhibition. Blood 2020;136:2080-89.

35. Holter JC, Pischke SE, de Boer E, Lind A, Jenum S, Holten AR, et al. Systemic complement activation is associated with respiratory failure in COVID-19 hospitalized patients. Proc Natl Acad Sci USA 2020;117:25018-25.
36. Busch MH, Timmermans S, Nagy M, Visser M, Huckriede J, Aendekerk JP, et al. Neutrophils and contact activation of coagulation as potential drivers of covid-19. Circulation 2020; 142:1787-90.

37. Skendros P, Mitsios A, Chrysanthopoulou A, Mastellos DC, Metallidis S, Rafailidis $\mathrm{P}$, et al. Complement and tissue factorenriched neutrophil extracellular traps are key drivers in COVID19 immunothrombosis. J Clin Invest 2020;130:6151-57.

38. Yu J, Gerber GF, Chen H, Yuan X, Chaturvedi S, Braunstein EM, et al. Complement dysregulation is associated with severe COVID-19 illness. Haematologica 2021. https://doi.org/10. 3324/haematol.2021.279155.

39. Skendros P, Mitsios A, Chrysanthopoulou A, Mastellos DC, Metallidis S, Rafailidis P, et al. Complement and tissue factorenriched neutrophil extracellular traps are key drivers in COVID-19 immunothrombosis. J Clin Invest 2020;130:6151-7.

40. Gavriilaki E, Brodsky RA. Complementopathies and precision medicine. J Clin Invest 2020;130:2152-63.

41. Valenti L, Griffini S, Lamorte G, Grovetti E, Uceda Renteria SC, Malvestiti F, et al. Chromosome 3 cluster rs11385942 variant links complement activation with severe COVID-19. J Autoimmun 2021;117:102595.

42. Ramlall V, Thangaraj PM, Meydan C, Foox J, Butler D, Kim J, et al. Immune complement and coagulation dysfunction in adverse outcomes of SARS-CoV-2 infection. Nat Med 2020;26:1609-15.

43. Diurno F, Numis FG, Porta G, Cirillo F, Maddaluno S, Ragozzino A, et al. Eculizumab treatment in patients with COVID-19: preliminary results from real life ASL Napoli 2 Nord experience. Eur Rev Med Pharmacol Sci 2020;24:4040-7.

44. Mastaglio S, Ruggeri A, Risitano AM, Angelillo P, Yancopoulou D, Mastellos DC. The first case of COVID-19 treated with the complement C3 inhibitor AMY-101. Clin Immunol 2020;215: 108450.

45. Rambaldi A, Gritti G, Mico MC, Frigeni M, Borleri G, Salvi A, et al. Endothelial injury and thrombotic microangiopathy in COVID-19: treatment with the lectin-pathway inhibitor narsoplimab. Immunobiology 2020;225:152001.

46. Mastellos DC, da Silva P, Fonseca BAL, Fonseca NP, AuxiliadoraMartins M, Mastaglio S, et al. Complement $\mathrm{C} 3$ vs $\mathrm{C} 5$ inhibition in severe COVID-19: early clinical findings reveal differential biological efficacy. Clin Immunol 2020;220:108598.

47. Chen L, Li X, Chen M, Feng Y, Xiong C. The ACE2 expression in human heart indicates new potential mechanism of heart injury among patients infected with SARS-CoV-2. Cardiovasc Res 2020;116:1097-1100.

48. Wan Y, Shang J, Graham R, Baric RS, Li F. Receptor recognition by the novel coronavirus from Wuhan: an analysis based on decade-long structural studies of SARS coronavirus. J Virol 2020;94. https://doi.org/10.1128/JVI.00127-20.

49. Heyman I, Liang H, Hedderly T. COVID-19 related increase in childhood tics and tic-like attacks. Arch Dis Child 2021. https:// doi.org/10.1136/archdischild-2021-321748. 33677431.

50. Netland J, Meyerholz DK, Moore S, Cassell M, Perlman S. Severe acute respiratory syndrome coronavirus infection causes neuronal death in the absence of encephalitis in mice transgenic for human ACE2. J Virol 2008;82:7264-75.

51. Baig AM, Khaleeq A, Ali U, Syeda H. Evidence of the COVID-19 virus targeting the CNS: tissue distribution, host-virus interaction, and proposed neurotropic mechanisms. ACS Chem Neurosci 2020;11:995-8. 
52. Paniz-Mondolfi A, Bryce C, Grimes Z, Gordon RE, Reidy J, Lednicky J, et al. Central nervous system involvement by severe acute respiratory syndrome coronavirus - 2 (SARS-CoV-2). J Med Virol 2020;92:699-702.

53. Pappas G, Christou L, Akritidis N, Tsianos EV. Quinolones for brucellosis: treating old diseases with new drugs. Clin Microbiol Infect 2006;12:823-5.

54. Kowalewski M, Fina D, Slomka A, Raffa GM, Martucci G, Lo Coco V, et al. COVID-19 and ECMO: the interplay between coagulation and inflammation-a narrative review. Crit Care 2020;24:205.

55. Davalos D, Akassoglou K. Fibrinogen as a key regulator of inflammation in disease. Semin Immunopathol 2012;34:43-62.

56. Al-Samkari H, Karp Leaf RS, Dzik WH, Carlson JCT, Fogerty AE, Waheed A, et al. COVID-19 and coagulation: bleeding and thrombotic manifestations of SARS-CoV-2 infection. Blood 2020;136:489-500.

57. Bryckaert M, Rosa JP, Denis CV, Lenting PJ. Of von Willebrand factor and platelets. Cell Mol Life Sci 2015;72:307-26.

58. Gragnano F, Sperlongano S, Golia E, Natale F, Bianchi R, Crisci $M$, et al. The role of von Willebrand factor in vascular inflammation: from pathogenesis to targeted therapy. Mediat Inflamm 2017;2017:5620314.

59. Buchtele N, Schwameis M, Gilbert JC, Schorgenhofer C, Jilma B. Targeting von Willebrand factor in Ischaemic stroke: focus on clinical evidence. Thromb Haemostasis 2018;118:959-78.

60. Kalagara T, Moutsis T, Yang Y, Pappelbaum KI, Farken A, Cladder-Micus $L$, et al. The endothelial glycocalyx anchors von Willebrand factor fibers to the vascular endothelium. Blood Adv 2018;2:2347-57.

61. Lazzari MA, Sanchez-Luceros A, Woods Al, Alberto MF, Meschengieser SS. Von Willebrand factor (vWF) as a risk factor for bleeding and thrombosis. Hematology 2012;17(1 Suppl): S150-2.

62. Ramapanicker R, Sun X, Viljanen J, Baltzer L. Powerful binders for the D-dimer by conjugation of the GPRP peptide to polypeptides from a designed set-illustrating a general route to new binders for proteins. Bioconjugate Chem 2013;24:17-25.

63. Wada H, Sakuragawa N. Are fibrin-related markers useful for the diagnosis of thrombosis? Semin Thromb Hemost 2008;34:33-8.

64. Guzik TJ, Mohiddin SA, Dimarco A, Patel V, Savvatis K, MarelliBerg FM, et al. COVID-19 and the cardiovascular system: implications for risk assessment, diagnosis, and treatment options. Cardiovasc Res 2020;116:1666-87.

65. Bularga A, Chapman AR, Mills NL. Mechanisms of myocardial injury in COVID-19. Clin Chem 2021;67:1044-6.

66. Blann AD, Nadar SK, Lip GY. The adhesion molecule P-selectin and cardiovascular disease. Eur Heart J 2003;24:2166-79.

67. Cambien B, Wagner DD. A new role in hemostasis for the adhesion receptor P-selectin. Trends Mol Med 2004;10:179-86.

68. Panicker SR, Mehta-D'souza P, Zhang N, Klopocki AG, Shao B, McEver RP. Circulating soluble P-selectin must dimerize to promote inflammation and coagulation in mice. Blood 2017;130: 181-91.

69. Kyrle PA, Hron G, Eichinger S, Wagner O. Circulating P-selectin and the risk of recurrent venous thromboembolism. Thromb Haemostasis 2007;97:880-3.

70. Gavriilaki E, Brodsky RA. Severe COVID-19 infection and thrombotic microangiopathy: success does not come easily. $\mathrm{Br}$ J Haematol 2020;189:e227-e30.
71. Ackermann M, Verleden SE, Kuehnel M, Haverich A, Welte T, Laenger $F$, et al. Pulmonary vascular endothelialitis, thrombosis, and angiogenesis in covid-19. N Engl J Med 2020;383:120-8.

72. Lowenstein CJ, Solomon SD. Severe COVID-19 is a microvascular disease. Circulation 2020;142:1609-11.

73. Ciceri F, Beretta L, Scandroglio AM, Colombo S, Landoni G, Ruggeri A, et al. Microvascular COVID-19 lung vessels obstructive thromboinflammatory syndrome (MicroCLOTS): an atypical acute respiratory distress syndrome working hypothesis. Crit Care Resusc 2020;22:95-7.

74. Porfidia A, Valeriani E, Pola R, Porreca E, Rutjes AWS, Di Nisio M. Venous thromboembolism in patients with COVID-19: systematic review and meta-analysis. Thromb Res 2020;196:67-74.

75. Hasan SS, Radford S, Kow CS, Zaidi STR. Venous thromboembolism in critically ill COVID-19 patients receiving prophylactic or therapeutic anticoagulation: a systematic review and meta-analysis. J Thromb Thrombolysis 2020;50:814-21.

76. Di Minno A, Ambrosino P, Calcaterra I, Di Minno MND. COVID-19 and venous thromboembolism: a meta-analysis of literature studies. Semin Thromb Hemost 2020;46:763-71.

77. Nopp S, Moik F, Jilma B, Pabinger I, Ay C. Risk of venous thromboembolism in patients with COVID-19: a systematic review and meta-analysis. Res Pract Thromb Haemost 2020;4: 1178-91.

78. Chi G, Lee JJ, Jamil A, Gunnam V, Najafi H, Memar Montazerin S, et al. Venous thromboembolism among hospitalized patients with COVID-19 undergoing thromboprophylaxis: a systematic review and meta-analysis. J Clin Med 2020;9. https://doi.org/ $10.3390 / \mathrm{jcm} 9082489$

79. Lu YF, Pan LY, Zhang WW, Cheng F, Hu SS, Zhang X, et al. A metaanalysis of the incidence of venous thromboembolic events and impact of anticoagulation on mortality in patients with COVID-19. Int J Infect Dis 2020;100:34-41.

80. Wu T, Zuo Z, Yang D, Luo X, Jiang L, Xia Z, et al. Venous thromboembolic events in patients with COVID-19: a systematic review and meta-analysis. Age Ageing 2021;50:284-93.

81. Malas MB, Naazie IN, Elsayed N, Mathlouthi A, Marmor R, Clary B. Thromboembolism risk of COVID-19 is high and associated with a higher risk of mortality: a systematic review and metaanalysis. EClinicalMedicine 2020;29:100639.

82. Zhang C, Shen L, Le KJ, Pan MM, Kong LC, Gu ZC, et al. Incidence of venous thromboembolism in hospitalized coronavirus disease 2019 patients: a systematic review and meta-analysis. Front Cardiovasc Med 2020;7:151.

83. Kollias A, Kyriakoulis KG, Lagou S, Kontopantelis E, Stergiou GS, Syrigos K. Venous thromboembolism in COVID-19: a systematic review and meta-analysis. Vasc Med 2021;26:415-25.

84. Boonyawat $K$, Chantrathammachart $P$, Numthavaj $P$, Nanthatanti N, Phusanti S, Phuphuakrat A, et al. Incidence of thromboembolism in patients with COVID-19: a systematic review and meta-analysis. Thromb J 2020;18:34.

85. Jimenez D, Garcia-Sanchez A, Rali P, Muriel A, Bikdeli B, RuizArtacho $P$, et al. Incidence of VTE and bleeding among hospitalized patients with coronavirus disease 2019: a systematic review and meta-analysis. Chest 2021;159:1182-96.

86. Sarfraz A, Sarfraz Z, Razzack AA, Patel G, Sarfraz M. Venous thromboembolism, corticosteroids and COVID-19: a systematic review and meta-analysis. Clin Appl Thromb Hemost 2021;27: 1076029621993573. 
87. Wang C, Zhang H, Zhou M, Cheng Y, Ye L, Chen J, et al. Prognosis of COVID-19 in patients with vein thrombosis: a systematic review and meta-analysis. Eur Rev Med Pharmacol Sci 2020;24: 10279-85.

88. Mansory EM, Srigunapalan S, Lazo-Langner A. Venous thromboembolism in hospitalized critical and noncritical COVID-19 patients: a systematic review and meta-analysis. $\mathrm{TH}$ Open 2021;5:e286-e94.

89. Zhang R, Ni L, Di X, Wang X, Ma B, Niu S, et al. Systematic review and meta-analysis of the prevalence of venous thromboembolic events in novel coronavirus disease-2019 patients. J Vasc Surg Venous Lymphat Disord 2021;9:289-98.e5.

90. Mohamed MFH, Al-Shokri SD, Shunnar KM, Mohamed SF, Najim MS, Ibrahim SI, et al. Prevalence of venous thromboembolism in critically ill COVID-19 patients: systematic review and metaanalysis. Front Cardiovasc Med 2020;7:598846.

91. Mai V, Tan BK, Mainbourg S, Potus F, Cucherat M, Lega JC, et al. Venous thromboembolism in COVID-19 compared to nonCOVID-19 cohorts: a systematic review with meta-analysis. Vasc Pharmacol 2021;139:106882.

92. Barnes GD, Burnett A, Allen A, Blumenstein M, Clark NP, Cuker A, et al. Thromboembolism and anticoagulant therapy during the COVID-19 pandemic: interim clinical guidance from the anticoagulation forum. J Thromb Thrombolysis 2020;50:72-81.

93. Spyropoulos AC, Levy JH, Ageno W, Connors JM, Hunt BJ, Iba T, et al. Scientific and standardization committee communication: clinical guidance on the diagnosis, prevention and treatment of venous thromboembolism in hospitalized patients with COVID19. J Thromb Haemostasis 2020;18:1859-65.

94. Spyropoulos AC, Levy JH, Ageno W, Connors JM, Hunt BJ, Iba T, et al. Scientific and Standardization Committee communication: clinical guidance on the diagnosis, prevention, and treatment of venous thromboembolism in hospitalized patients with COVID-19. J Thromb Haemostasis 2020;18:1859-65.

95. Zhai Z, Li C, Chen Y, Gerotziafas G, Zhang Z, Wan J, et al. Prevention and treatment of venous thromboembolism associated with coronavirus disease 2019 infection: a consensus statement before guidelines. Thromb Haemostasis 2020;120:937-48.

96. Sanchez JB, Cuipal Alcalde JD, Ramos Isidro R, Luna CZ, Cubas WS, Coaguila Charres A, et al. Acute limb ischemia in a Peruvian cohort infected by COVID-19. Ann Vasc Surg 2021;72:196-204.

97. Topcu AC, Ozturk-Altunyurt G, Akman D, Batirel A, Demirhan R. Acute limb ischemia in hospitalized COVID-19 patients. Ann Vasc Surg 2021;74:88-94.

98. Bellosta R, Luzzani L, Natalini G, Pegorer MA, Attisani L, Cossu LG, et al. Acute limb ischemia in patients with COVID-19 pneumonia. J Vasc Surg 2020;72:1864-72.

99. Huang C, Wang Y, Li X, Ren L, Zhao J, Hu Y, et al. Clinical features of patients infected with 2019 novel coronavirus in Wuhan, China. Lancet 2020;395:497-506.

100. Sabatino J, De Rosa S, Di Salvo G, Indolfi C. Impact of cardiovascular risk profile on COVID-19 outcome. A metaanalysis. PLoS One 2020;15:e0237131.

101. Zhao YH, Zhao L, Yang XC, Wang P. Cardiovascular complications of SARS-CoV-2 infection (COVID-19): a systematic review and meta-analysis. Rev Cardiovasc Med 2021;22:159-65.

102. Koeppen M, Rosenberger P, Magunia H. COVID-19 related cardiovascular comorbidities and complications in critically ill patients: a systematic review and meta-analysis. Clin Med Insights Circulatory, Respir Pulm Med 2021;15: 1179548421992327.

103. Wu ZH, Tang Y, Cheng Q. Diabetes increases the mortality of patients with COVID-19: a meta-analysis. Acta Diabetol 2021;58: 139-44.

104. Pranata R, Lim MA, Huang I, Raharjo SB, Lukito AA. Hypertension is associated with increased mortality and severity of disease in COVID-19 pneumonia: a systematic review, meta-analysis and meta-regression. J Renin-Angiotensin-Aldosterone Syst JRAAS 2020;21:1470320320926899.

105. Yang J, Tian C, Chen Y, Zhu C, Chi H, Li J. Obesity aggravates COVID-19: an updated systematic review and meta-analysis. J Med Virol 2021;93:2662-74.

106. Wang Z, Deng H, Ou C, Liang J, Wang Y, Jiang M, et al. Clinical symptoms, comorbidities and complications in severe and nonsevere patients with COVID-19: a systematic review and metaanalysis without cases duplication. Medicine 2020;99:e23327.

107. Toraih EA, Elshazli RM, Hussein MH, Elgaml A, Amin M, ElMowafy $M$, et al. Association of cardiac biomarkers and comorbidities with increased mortality, severity, and cardiac injury in COVID-19 patients: a meta-regression and decision tree analysis. J Med Virol 2020;92:2473-88.

108. Sahranavard M, Akhavan Rezayat A, Zamiri Bidary M, Omranzadeh A, Rohani F, Hamidi Farahani R, et al. Cardiac complications in COVID-19: a systematic review and metaanalysis. Arch Iran Med 2021;24:152-63.

109. Romiti GF, Corica B, Lip GYH, Proietti M. Prevalence and impact of atrial fibrillation in hospitalized patients with COVID-19: a systematic review and meta-analysis. J Clin Med 2021;10. https://doi.org/10.3390/jcm10112490.

110. De Michieli L, Ola O, Knott JD, Akula A, Mehta RA, Hodge DO, et al. High-sensitivity cardiac troponin T for the detection of myocardial injury and risk stratification in COVID-19. Clin Chem 2021;67:1080-9.

111. Vakhshoori M, Heidarpour M, Shafie D, Taheri M, Rezaei N, Sarrafzadegan N. Acute cardiac injury in COVID-19: a systematic review and meta-analysis. Arch Iran Med 2020;23:801-12.

112. Fu L, Liu X, Su Y, Ma J, Hong K. Prevalence and impact of cardiac injury on COVID-19: a systematic review and meta-analysis. Clin Cardiol 2021;44:276-83.

113. Santoso A, Pranata R, Wibowo A, Al-Farabi MJ, Huang I, Antariksa B. Cardiac injury is associated with mortality and critically ill pneumonia in COVID-19: a meta-analysis. Am J Emerg Med 2021; 44:352-7.

114. Avula A, Nalleballe K, Narula N, Sapozhnikov S, Dandu V, Toom $\mathrm{S}$, et al. COVID-19 presenting as stroke. Brain Behav Immun 2020;87:115-19.

115. Siow I, Lee KS, Zhang JJY, Saffari SE, Ng A, Young B. Stroke as a neurological complication of COVID-19: a systematic review and meta-analysis of incidence, outcomes and predictors. J Stroke Cerebrovasc Dis 2021;30:105549.

116. Yassin A, Nawaiseh M, Shaban A, Alsherbini K, El-Salem K, Soudah O, et al. Neurological manifestations and complications of coronavirus disease 2019 (COVID-19): a systematic review and meta-analysis. BMC Neurol 2021;21:138.

117. Vakili K, Fathi M, Hajiesmaeili M, Salari M, Saluja D, Tafakhori A, et al. Neurological symptoms, comorbidities, and complications of COVID-19: a literature review and meta-analysis of observational studies. Eur Neurol 2021;84:307-24. 
118. Lee KW, Yusof Khan AHK, Ching SM, Chia PK, Loh WC, Abdul Rashid AM, et al. Stroke and novel coronavirus infection in humans: a systematic review and meta-analysis. Front Neurol 2020;11:579070.

119. Siepmann T, Sedghi A, Simon E, Winzer S, Barlinn J, de With K, et al. Increased risk of acute stroke among patients with severe COVID-19: a multicenter study and meta-analysis. Eur J Neurol 2021;28:238-47.

120. Zhang J, Wang H, Wei M, Zhang H, Xia B, Wang X, et al. Incidence of cerebrovascular disease as a comorbidity in patients with COVID-19: a meta-analysis. Aging 2020;12:23450-63.

121. Parsay S, Vosoughi A, Khabbaz A, Sadigh-Eteghad S. The incidence and mortality ratio of ischemic cerebrovascular accidents in COVID-19 cases: a systematic review and metaanalysis. J Stroke Cerebrovasc Dis 2021;30:105552.

122. Benussi A, Pilotto A, Premi E, Libri I, Giunta M, Agosti C, et al. Clinical characteristics and outcomes of inpatients with neurologic disease and COVID-19 in Brescia. Lombardy, Italy. Neurology 2020;95:e910-e920.

123. Romero-Sánchez CM, Díaz-Maroto I, Fernández-Díaz E, SánchezLarsen Á, Layos-Romero A, García-García J, et al. Neurologic manifestations in hospitalized patients with COVID-19: the ALBACOVID registry. Neurology 2020;95:e1060-e1070.

124. UK-wide surveillance of neurological and neuropsychiatric complications of COVID-19: the first 153 patients [Internet]; 2020 [cited 29/5/2020]. Available from: https://ssrn.com/ abstract $=3601761$.

125. Sharifi-Razavi A, Karimi N, Rouhani N. COVID-19 and intracerebral haemorrhage: causative or coincidental? New Microbes New Infect 2020;35. https://doi.org/10.1016/j.nmni. 2020.100669.

126. Helms J, Tacquard C, Severac F, Leonard-Lorant I, Ohana M, Delabranche $X$, et al. High risk of thrombosis in patients with severe SARS-CoV-2 infection: a multicenter prospective cohort study. Intensive Care Med 2020;46:1089-98.

127. Favas TT, Dev P, Chaurasia RN, Chakravarty K, Mishra R, Joshi D, et al. Neurological manifestations of COVID-19: a systematic review and meta-analysis of proportions. Neurol Sci 2020;41: 3437-70.

128. Collantes MEV, Espiritu AI, Sy MCC, Anlacan VMM, Jamora RDG. Neurological manifestations in COVID-19 infection: a systematic review and meta-analysis. Can J Neurol Sci 2021; 48:66-76.

129. Chua TH, Xu Z, King NKK. Neurological manifestations in COVID-19: a systematic review and meta-analysis. Brain Inj 2020;34:1549-68.

130. Madani Neishaboori A, Moshrefiaraghi D, Mohamed Ali K, Toloui A, Yousefifard M, Hosseini M. Central nervous system complications in COVID-19 patients; a systematic review and meta-analysis based on current evidence. Arch Acad Emerg Med 2020;8:e62.

131. The L. Facing up to long COVID. Lancet 2020;396:1861.

132. Raveendran AV. Long COVID-19: challenges in the diagnosis and proposed diagnostic criteria. Diabetes Metab Syndr 2021;15:145-6.

133. Kamal M, Abo Omirah M, Hussein A, Saeed H. Assessment and characterisation of post-COVID-19 manifestations. Int J Clin Pract 2021;75:e13746.
134. Townsend L, Moloney D, Finucane C, McCarthy K, Bergin C, Bannan C, et al. Fatigue following COVID-19 infection is not associated with autonomic dysfunction. PLoS One 2021;16: e0247280.

135. Venkatesan P. NICE guideline on long COVID. Lancet Respir Med 2021;9:129.

136. Kresch E, Achua J, Saltzman R, Khodamoradi K, Arora H, Ibrahim $E$, et al. COVID-19 endothelial dysfunction can cause erectile dysfunction: histopathological, immunohistochemical, and ultrastructural study of the human penis. World J Mens Health 2021:39:466-9.

137. Lee CCE, Ali K, Connell D, Mordi IR, George J, Lang EM, et al. COVID-19-associated cardiovascular complications. Diseases 2021;9. https://doi.org/10.3390/diseases9030047.

138. Ergul E, Yilmaz AS, Ogutveren MM, Emlek N, Kostakoglu U, Cetin M. COVID 19 disease independently predicted endothelial dysfunction measured by flow-mediated dilatation. Int I Cardiovasc Imag 2021; 1-8. https://doi.org/10.1007/s10554-021-02356-3.

139. Lu X, Zhang L, Du H, Zhang J, Li YY, Qu J, et al. SARS-CoV-2 infection in children. N Engl J Med 2020;382:1663-5.

140. Verdoni L, Mazza A, Gervasoni A, Martelli L, Ruggeri M, Ciuffreda $M$, et al. An outbreak of severe Kawasaki-like disease at the Italian epicentre of the SARS-CoV-2 epidemic: an observational cohort study. Lancet 2020;395:1771-8.

141. Riphagen S, Gomez X, Gonzalez-Martinez C, Wilkinson N, Theocharis P. Hyperinflammatory shock in children during COVID-19 pandemic. Lancet 2020;395:1607-8.

142. Whittaker E, Bamford A, Kenny J, Kaforou M, Jones CE, Shah P, et al. Clinical characteristics of 58 children with a pediatric inflammatory multisystem syndrome temporally associated with SARS-CoV-2. J Am Med Assoc 2020;324:259-69.

143. Cheung EW, Zachariah P, Gorelik M, Boneparth A, Kernie SG, Orange JS, et al. Multisystem inflammatory syndrome related to COVID-19 in previously healthy children and adolescents in New York city. J Am Med Assoc 2020;324:294-6.

144. Feldstein LR, Rose EB, Horwitz SM, Collins JP, Newhams MM, Son MBF, et al. Multisystem inflammatory syndrome in U.S. children and adolescents. N Engl J Med 2020;383:334-46.

145. Dufort EM, Koumans EH, Chow EJ, Rosenthal EM, Muse A, Rowlands J, et al. Multisystem inflammatory syndrome in children in New York state. N Engl J Med 2020;383:347-58.

146. Newburger JW, Takahashi M, Burns JC. Kawasaki disease. J Am Coll Cardiol 2016;67:1738-49.

147. Rowley AH, Baker SC, Orenstein JM, Shulman ST. Searching for the cause of Kawasaki disease-cytoplasmic inclusion bodies provide new insight. Nat Rev Microbiol 2008;6:394-401.

148. Tetro JA. Is COVID-19 receiving ADE from other coronaviruses? Microb Infect 2020;22:72-3.

149. Whitworth H, Sartain SE, Kumar R, Armstrong K, Ballester L, Betensky $M$, et al. Rate of thrombosis in children and adolescents hospitalized with COVID-19 or MIS-C. Blood 2021; 138:190-8

150. Stephenson T, Shafran R, De Stavola B, Rojas N, Aiano F, Amin-Chowdhury Z, et al. Long COVID and the mental and physical health of children and young people: national matched cohort study protocol (the CLoCk study). BMJ Open 2021;11:e052838. 